\title{
ESTUDO COMPARATIVO DO PERFIL DE ÁCIDOS GRAXOS PRESENTES NO ÓLEO EXTRAÍDO DAS SEMENTES DE GOIABA (Psidium guajava L.)
}

\author{
M. L. R. SILVEIRA ${ }^{1}$, C. O. SANTOS ${ }^{1}$, J. M. CREMONESE ${ }^{1}$, J. P. FORTES ${ }^{1}$, C. K. \\ SAUTTER $^{1}$, N. G. PENNA ${ }^{1}$ \\ ${ }^{1}$ Universidade Federal de Santa Maria, Departamento de Tecnologia e Ciência dos Alimentos. \\ E-mail para contato: marciarippel@gmail.com
}

\begin{abstract}
RESUMO - Na indústria, durante a conversão das frutas in natura em produtos industrializados são gerados e recolhidos materiais não aproveitados na produção industrial, os chamados coprodutos. Estudos têm sido conduzidos com o intuito de investigar o valor nutricional desses materiais, valorizando-os e sugerindo novas alternativas de utilização. O objetivo deste estudo foi determinar o teor de óleo extraído das sementes de goiaba, identificar e quantificar os principais ácidos graxos presentes na fração, comparando o perfil lipídico obtido das extrações realizadas com diferentes solventes. O óleo foi extraído das sementes de goiaba do genótipo de polpa vermelha (Psidium guajava L. var. Paluma), em um extrator Soxhlet utilizando como solventes o $n$-hexano, éter de petróleo e éter etílico. A composição dos ácidos graxos presentes na fração lipídica foi determinada por cromatografia a gás, usando detector de ionização em chama. O melhor rendimento em óleo foi obtido para a extração com éter etílico, a maior quantidade de ácidos graxos identificados foi verificada no óleo extraído com $n$-hexano e éter etílico. Estas extrações também apresentaram a maior concentração de gordura saturada, enquanto que o óleo extraído com éter de petróleo obteve elevada porcentagem de ácidos graxos insaturados. Os ácidos graxos encontrados em maior abundância para todos os solventes empregados foram o esteárico, o elaídico, o linoleico e o palmítico, porém este último ausente na extração com éter de petróleo.
\end{abstract}

\section{INTRODUÇÃO}

O Brasil é um dos maiores produtores mundiais de goiaba (Psidium guajava L.), em regiões tropicais e subtropicais a goiaba é um dos frutos de maior importância não só devido ao seu elevado valor nutritivo, mas também pela excelente aceitação do consumo in natura favorecido pelas suas características de sabor e aroma além, da sua grande aplicação industrial. A maior parte da produção brasileira de goiabas destina-se a atender a demanda industrial para a elaboração de diversos produtos, como doces, sucos, geleias, polpa congelada, entre outros. No entanto, durante as etapas do processo de beneficiamento dos frutos são recolhidos materiais não aproveitados na produção industrial, os chamados coprodutos. A quase totalidade desses coprodutos é constituída pelas cascas e sementes da fruta e representam um problema tecnológico de grandes proporções para a indústria de alimentos, uma vez que precisam ser descartados 
(UCHOA et al. 2008; AQUINO et al. 2010; NASCIMENTO; ARAÚJO; MELO, 2010; MELO et al. 2011).

O elevado índice de perdas e desperdícios e a crescente preocupação com os possíveis impactos ambientais reforçam a necessidade de buscar alternativas para o aproveitamento dos coprodutos, e tem motivado muitos pesquisadores a estudar alternativas para a utilização dos mesmos (ISHIMOTO et al. 2007). Neste sentido, diversos trabalhos sobre a composição dos coprodutos gerados pela indústria de alimentos vêm sendo realizados com a finalidade de conhecer seus constituintes para que esses sejam adequadamente aproveitados.

Alguns autores sugerem que o aproveitamento das sementes obtidas do processamento da goiaba para a extração de óleo poderia aumentar a renda sobre a matéria-prima e agregaria valor a este coproduto, fortalecendo a cadeia produtiva desta fruta. Além disso, ajudaria a minimizar o problema que a deposição desses materiais pode causar, tendo em vista os elevados volumes gerados pelas indústrias no processamento da fruta, acrescido à necessidade de se expandir a produção de alimentos para a população (KOBORI; JORGE, 2005).

$\mathrm{Na}$ literatura, os dados sobre a composição química da semente de goiaba indicam um conteúdo de óleo entre 8 e 16\%, sendo estes valores variáveis em função da variedade, processamento e condições de cultura (FONTANARI et al. 2007). Prasad e Azeemoddin (1994) constataram que o óleo obtido das sementes de goiaba é uma boa fonte de ácido linoleico (76,4\%) como ácido graxo essencial, podendo ser utilizado com vantagens nutricionais. Ao estudarem as propriedades físico-químicas e a composição dos ácidos graxos de óleos extraídos de sementes de quatro variedades de goiaba, Macedo et al. (1994) observaram certa semelhança em relação as constantes físico-químicas nas quatro variedades em estudo e verificaram a predominância de ácidos graxos insaturados, com destaque para o alto conteúdo de ácido linoleico $(76,26 \%$, $78,70 \%, 78,80 \%$ e 79,82\%). Em relação à saúde, a composição em ácidos graxos dos alimentos é de grande importância, principalmente os ácidos graxos insaturados, pois ao seu consumo são atribuídos numerosos benefícios ao organismo humano. Além disso, os ácidos graxos mono e poli-insaturados são essenciais para o corpo humano, já que não podem ser sintetizados pelo organismo (LUZIA; JORGE, 2009; ROCKENBACH et al. 2010).

O estudo detalhado sobre a composição do óleo das sementes de goiaba contribui para a obtenção de dados sobre a composição dos ácidos graxos de sua fração lipídica, proporcionando informações técnico-científicas para o aproveitamento das sementes. Diante do exposto, o presente estudo objetivou determinar o teor de óleo extraído das sementes de goiaba, identificar e quantificar os principais ácidos graxos presentes na fração lipídica, comparando o perfil lipídico obtido das extrações realizadas com diferentes solventes.

\section{MATERIAL E MÉTODOS}

Para a realização deste trabalho foram utilizadas amostras de sementes de goiaba do genótipo de polpa vermelha (Psidium guajava L. var. Paluma), separadas da polpa manualmente com o auxílio de peneiras. As sementes foram secas em estufa de circulação 


\section{9 a 22 de outubro de 2014 \\ Florianópolis/SC}

forçada de ar a $55^{\circ} \mathrm{C}$ por $3 \mathrm{~h}$, após resfriamento, o material seco foi triturado em micromoinho (Marconi, modelo MA - 630) e utilizado para a extração do óleo da semente de goiaba.

A fração lipídica foi extraída das sementes em extrator Soxhlet, utilizando como solventes o $n$-hexano, éter de petróleo e éter etílico, por um período de 6 horas, como descrito nas Normas Analíticas do Instituto Adolfo Lutz (IAL, 2008). Após este período, o solvente foi removido em evaporador rotativo e a massa de óleo obtida por pesagem em balança analítica foi utilizada para efetuar o cálculo do rendimento das extrações. Os resultados expressos em porcentagem foram calculados sobre o peso da amostra seca ( $\mathrm{g}$ de óleo/100 $\mathrm{g}$ de amostra seca).

Para a análise de composição de ácidos graxos, a fração lipídica total foi submetida à metilação dos ácidos graxos, segundo Hartman e Lago (1973). A análise dos ésteres metílicos dos ácidos graxos foi realizada em cromatógrafo gasoso (Agilent Technologies, modelo 6890N), equipado com detector de ionização de chama, injetor split operando em razão de 50:1, coluna capilar de sílica fundida SP-2560 (100m x 0,25mm x 0,20 $\mu \mathrm{m}$, Supelco $\left.{ }^{\circledR}\right)$, nas seguintes condições cromatográficas: temperatura do injetor $250^{\circ} \mathrm{C}$; temperatura da coluna $90{ }^{\circ} \mathrm{C}$ por 2 minutos, com incremento de $6{ }^{\circ} \mathrm{C} / \mathrm{min}$. até $170{ }^{\circ} \mathrm{C}(2$ minutos $)$, então aumentou $3{ }^{\circ} \mathrm{C} / \mathrm{min}$. até 185 ${ }^{\circ} \mathrm{C}$ (6 minutos) e após aumentou com um gradiente de temperatura de $5{ }^{\circ} \mathrm{C} / \mathrm{min}$. até $240{ }^{\circ} \mathrm{C}$, permanecendo estável por 13 minutos; temperatura do detector $250{ }^{\circ} \mathrm{C}$; gás de arraste nitrogênio com fluxo de $1 \mathrm{~mL}$.min-1 mantido por 39 minutos, seguido de aumento de $2 \mathrm{~mL}$.min-1 até 20 minutos; e volume de injeção de $1 \mu \mathrm{L}$. Para a identificação dos ácidos graxos, foi realizada a comparação dos tempos de retenção dos picos dos cromatogramas das amostras com padrões puros de ésteres metílicos (37-componet FAME Mix, Supelco ${ }^{\circledR}$ ). A quantificação foi realizada pela normalização de área, expressando-se o resultado em percentual de área de cada ácido sobre a área total de ácidos graxos (\%).

Todas as análises foram realizadas em triplicata e os resultados obtidos foram expressos na forma de média desvio padrão e submetidos à análise de variância (ANOVA). A análise comparativa dos resultados foi realizada por meio do teste de Tukey ao nível de significância de $5 \%$, utilizando o programa estatístico Statistic ${ }^{\circledR}$ versão 9.0.

\section{RESULTADOS E DISCUSSÃO}

A Figura 1 apresenta graficamente os resultados obtidos na extração da fração lipídica da semente de goiaba, empregando-se diferentes solventes.

No presente estudo comparativo avaliou-se qual dos solventes utilizados proporcionaria o melhor rendimento e qualidade da fração lipídica. Em relação ao rendimento, a quantidade de óleo obtida nas extrações realizadas em aparelho Soxhlet com os solventes éter de petróleo, $n$ hexano e éter etílico foram de 1,78; 2,04 e 5,50 g de óleo em $100 \mathrm{~g}$-1 amostra seca, respectivamente. A análise comparativa dos resultados demonstrou que não houve diferença estatística para o rendimento entre as extrações com éter de petróleo e $n$-hexano, mas ambas diferiram significativamente da extração com éter etílico que apresentou o maior rendimento em óleo. 
Em relação à extração de lipídios pelo método convencional de Soxhlet, diversos estudos já foram realizados com o objetivo de otimizar o método, a partir da modificação do procedimento operacional. De acordo com Brum (2004), a redução no tempo de extração, o menor consumo de energia, menor efeito sobre a qualidade da fração lipídica e um maior rendimento são algumas das preocupações em relação a essa metodologia secular, porém exaustivamente utilizada até os dias de hoje.

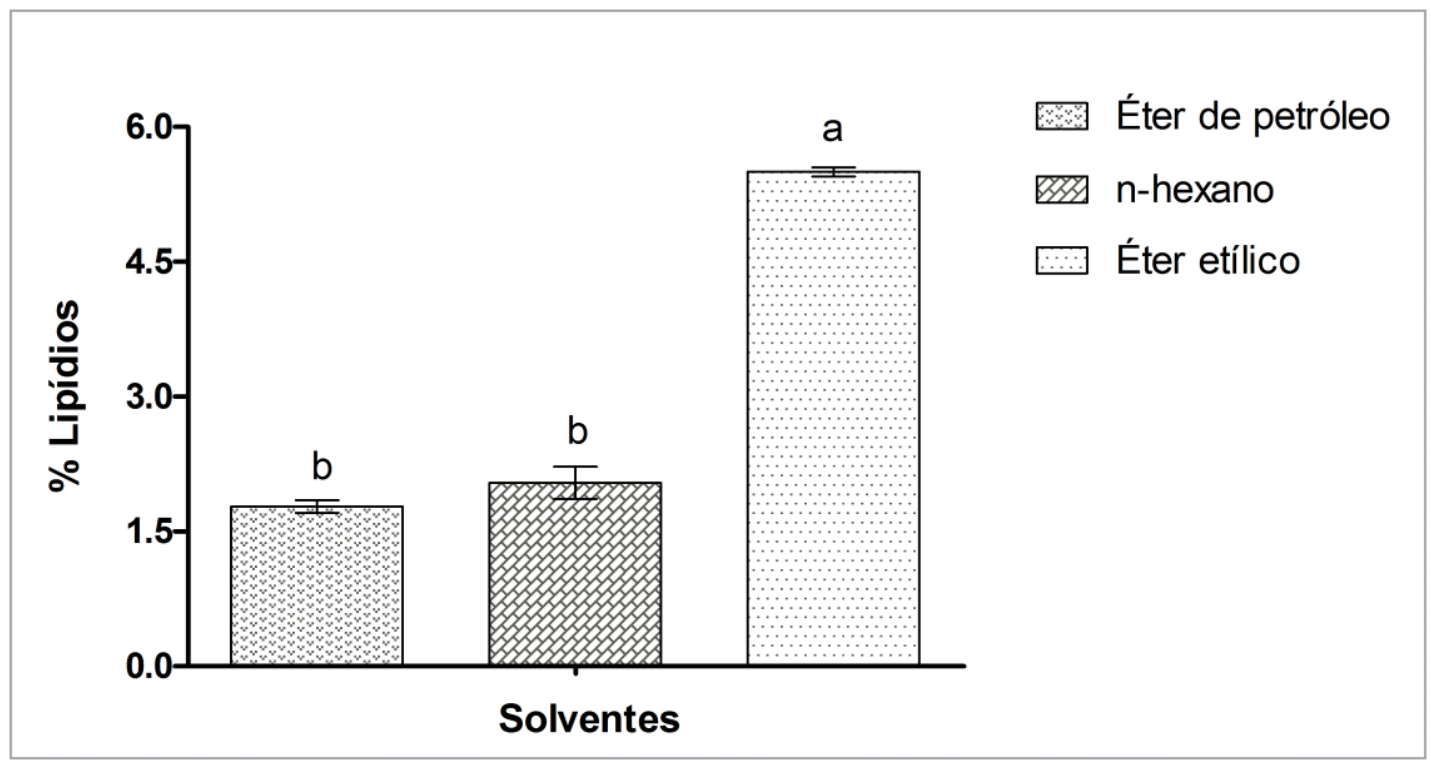

Figura 1 - Percentual de lipídios extraídos* da semente de goiaba empregando-se diferentes solventes na extração. *Barras com letras diferentes, diferem entre si pelo teste de Tukey $(\mathrm{p}<0,05)$.

No estudo de Luzia, Bertanha e Jorge (2010), Luzia e Jorge (2009) e Malacrida et al. (2007) os teores médios de lipídio encontrados para as sementes de pitanga, jambolão e melão amarelo em aparelho de Soxhlet, sem a indicação dos solventes utilizados foi de 3,2; 1,37 e 25,2 $\mathrm{g} 100 \mathrm{~g}^{-1}$, respectivamente.

O perfil de ácidos graxos do óleo das sementes de goiaba empregando-se diferentes solventes para a extração é apresentado na Tabela 1. As análises das diferentes frações lipídicas obtidas mostraram que a predominância de ácidos graxos variou conforme o solvente utilizado para a extração.

Como pode ser observado (Tabela 1), para os solventes, $n$-hexano e éter etílico, utilizados na extração foram identificados respectivamente 16 e 15 ácidos graxos no óleo da semente de goiaba. No que se refere à composição em ácidos graxos, os óleos extraídos com estes solventes apresentaram as maiores médias para os ácidos graxos saturados $(63,87$ e 66,01 \%, respectivamente), dentre estes, os principais quantitativamente foram o ácido palmítico e esteárico. Para cada extração, estes dois ácidos graxos citados representam juntos mais de 57\% do total de ácidos graxos saturados presentes no óleo da semente de goiaba. Além dos ácidos graxos saturados, foram também identificados nas extrações com $n$-hexano e éter etílico os ácidos 
graxos monoinsaturados (MUFA) e poli-insaturados (PUFAS). Na fração insaturada do óleo, predominaram os ácidos elaídico (15,94 e 14,62\%) e linoleico (18,90 e 18,01\%), no entanto, não houve diferença significativa $(\mathrm{p}<0,05)$ na concentração destes dois ácidos graxos em relação aos solventes utilizados na extração.

Tabela 1 - Composição em ácidos graxos (\%) da fração lipídica do óleo da semente de goiaba, empregando-se diferentes solventes na extração.

\begin{tabular}{|c|c|c|c|}
\hline \multirow{2}{*}{ Ácidos graxos (\%) } & \multicolumn{3}{|c|}{ Solventes* } \\
\hline & $n$-hexano & Éter etílico & Éter de petróleo \\
\hline Capróico (C6:0) & $1,11 \pm 0,10^{b}$ & $2,09 \pm 0,28^{a}$ & $1,24 \pm 0,04^{b}$ \\
\hline Caprílico (C8:0) & $1,08 \pm 0,03^{\mathrm{a}}$ & $1,24 \pm 0,20^{\mathrm{a}}$ & $1,40 \pm 0,53^{\mathrm{a}}$ \\
\hline Undecílico (C11:0) & $0,19 \pm 0,06^{\mathrm{a}}$ & nd & nd \\
\hline Mirístico $(\mathrm{C} 14 ; 0)$ & $0,63 \pm 0,11^{\mathrm{b}}$ & $0,43 \pm 0,14^{b}$ & $1,45 \pm 0,52^{\mathrm{a}}$ \\
\hline Pentadecanoico (C15:0) & nd & $0,20 \pm 0,03^{\mathrm{a}}$ & nd \\
\hline Palmítico (C16:0) & $37,03 \pm 0,20^{b}$ & $37,89 \pm 0,19^{\mathrm{a}}$ & nd \\
\hline Palmitoleico (C16:1) & $0,34 \pm 0,02^{b}$ & $0,48 \pm 0,08^{\mathrm{a}}$ & nd \\
\hline Margárico (C17:0) & $0,44 \pm 0,11^{\mathrm{a}}$ & $0,44 \pm 0,06^{\mathrm{a}}$ & $0,58 \pm 0,15^{\mathrm{a}}$ \\
\hline Esteárico (C18:0) & $20,07 \pm 0,13^{b}$ & $20,53 \pm 0,07^{\mathrm{b}}$ & $32,82 \pm 1,45^{\mathrm{a}}$ \\
\hline Elaídico (C18:1n9t) & $15,94 \pm 0,15^{\mathrm{b}}$ & $14,62 \pm 0,16^{\mathrm{b}}$ & $35,61 \pm 2,01^{\mathrm{a}}$ \\
\hline Linoleico $(\mathrm{C} 18: 2 \mathrm{n} 6 c)$ & $18,90 \pm 0,25^{b}$ & $18,01 \pm 0,18^{b}$ & $25,45 \pm 0,76^{\mathrm{a}}$ \\
\hline Araquídico (C20:0) & $1,92 \pm 0,17^{\mathrm{a}}$ & $2,03 \pm 0,19^{\mathrm{a}}$ & nd \\
\hline cis-11-Eicosenóico (C20:1n9) & $0,29 \pm 0,11^{\mathrm{a}}$ & $0,30 \pm 0,05^{\mathrm{a}}$ & nd \\
\hline cis-11,14-Eicosadienoico (C20:2) & $0,44 \pm 0,15^{\mathrm{a}}$ & $0,58 \pm 0,27^{\mathrm{a}}$ & nd \\
\hline Araquidônico (C20:4n6) & $0,32 \pm 0,10^{\mathrm{a}}$ & nd & nd \\
\hline Behênico (C22:0) & $0,63 \pm 0,13^{b}$ & $0,66 \pm 0,08^{b}$ & $1,45 \pm 0,07^{\mathrm{a}}$ \\
\hline Lignocérico (C24:0) & $0,75 \pm 0,08^{\mathrm{a}}$ & $0,50 \pm 0,09^{b}$ & nd \\
\hline$\Sigma$ Saturados & 63,87 & 66,01 & 38,94 \\
\hline$\Sigma$ Monoinsaturados (MUFA) & 16,56 & 15,40 & 35,61 \\
\hline$\Sigma$ Poli-insaturados (PUFA) & 19,66 & 18,59 & 25,45 \\
\hline$\Sigma$ Insaturados & 36,22 & 33,99 & 61,06 \\
\hline
\end{tabular}

*Médias com letras iguais na mesma linha não diferem entre si pelo teste de Tukey (p<0,05). Nd: não detectado. 


\section{9 a 22 de outubro de 2014 \\ Florianópolis/SC}

$\mathrm{Na}$ extração com éter de petróleo foram identificados apenas oito ácidos graxos na fração lipídica da semente de goiaba. O óleo analisado apresentou média de 38,94\% de ácidos graxos saturados, 35,61\% de monoinsaturados e 25,45\% de poli-insaturados, prevalecendo os ácidos graxos insaturados em relação aos saturados. No óleo das sementes de goiaba, os ácidos graxos encontrados em maior quantidade foram o esteárico $(32,82 \%)$, o elaídico $(35,61 \%)$ e o linoleico $(25,45 \%)$. Nos resultados, quando analisados estatisticamente, foram encontradas diferenças significativas $(\mathrm{p}<0,05)$ entre as concentrações destes ácidos graxos no óleo extraído com éter de petróleo e os teores verificados para as extrações com $n$-hexano e éter etílico, que não diferiram entre si.

O alto conteúdo de ácido linoleico é nutricionalmente importante, pois este é um ácido graxo essencial, precursor dos demais ácidos graxos da família ômega-6. O consumo de alimentos com MUFA e PUFA é importante para a diminuição das frações lipídicas de LDL (Lipoproteína de Baixa Densidade) e VLDL (Lipoproteína de Muito Baixa Densidade). Entretanto quando consumidos em excesso, podem induzir maior oxidação lipídica e diminuir o HDL (Lipoproteína de Alta Densidade) (LUZIA; JORGE, 2009).

Em recente estudo realizado por Santos (2011) sobre o perfil de ácidos graxos da semente de goiaba (Psidium guajava L.) oriunda de resíduos agroindustriais foi observado que $76,48 \%$ dos ácidos graxos presentes eram poli-insaturados, 12,16\% saturados e 11,36\% monoinsaturados. Os dados obtidos por este autor foram qualitativamente superiores se comparados com os resultados obtidos no presente trabalho, pois os ácidos graxos mais representativos foram o linoleico $(75,74 \%)$, oleico $(10,65 \%)$, palmítico $(7,04 \%)$ e esteárico $(5,05 \%)$. Desta forma, o autor sugere que este resíduo possui potencial para a suplementação de dietas, uma vez que, a semente de goiaba apresentou um interessante perfil cromatográfico em relação ao tipo e a quantidade de ácidos graxos presentes no óleo.

Em estudo realizado por Jardini e Mancini-Filho (2007), o perfil de ácidos graxos do óleo extraído das sementes de romã apresentou elevada quantidade de ácidos linoleico e oleico, perfazendo um total de $70,09 \%$ de ácidos graxos insaturados. No perfil de ácidos graxos das sementes de jambolão se destacaram os ácidos linoleico $(43,81 \%)$, palmítico $(24,06 \%)$ e o oleico (14,07\%). A quantidade total de ácidos graxos insaturados foi de $67,91 \%$, dos quais $24,10 \%$ de ácidos monoinsaturados e 43,81\% de ácidos poli-insaturados, sendo o ácido linoleico o principal componente (LUZIA; JORGE, 2009).

O óleo da semente de baru revelou-se altamente insaturado (81,2\%), o elevado grau de insaturação deveu-se à predominância dos ácidos oléico $(50,4 \%)$ e linoleico $(28,9 \%)$ (TAKEMOTO et al. 2001). No trabalho de Rockenbach et al. (2010), os ácidos graxos encontrados em maior abundância no óleo das sementes de bagaço de uva foram o linoleico, o oleico, o palmítico e o esteárico. Segundo os autores, a composição em ácidos graxos do óleo das sementes de uva foi similar à de óleos como açafrão, girassol, soja, milho e semente de algodão.

Luzia, Bertanha e Jorge (2010) identificaram por cromatografia gasosa os ácidos graxos presentes na fração lipídica das sementes de pitanga. O conteúdo total de ácidos graxos 


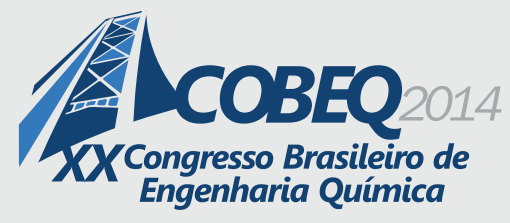

19 a 22 de outubro de 2014
Florianópolis/SC

insaturados foi de 58,06\%, entre os quais o ácido oleico obteve em média 38,29\% e o ácido linoleico uma média de 13,46\%. Os dois ácidos majoritários representam $89 \%$ dos ácidos insaturados, estando o restante em porcentagens muito inferiores. Entre os ácidos graxos saturados, o ácido palmítico apresentou quantidades significativas (34,09\%).

\section{CONCLUSÃO}

Dentre as extrações realizadas com diferentes solventes em aparelho de Soxhlet, o melhor rendimento em óleo foi obtido na extração com éter etílico. Já os resultados obtidos no perfil de ácidos graxos do óleo das sementes de goiaba demonstraram que as extrações com $n$-hexano e éter etílico obtiveram a maior quantidade de ácidos graxos identificados. O óleo obtido destas extrações também apresentou a maior concentração de gordura saturada, enquanto que o óleo extraído com éter de petróleo obteve elevada porcentagem de ácidos graxos insaturados. Os ácidos graxos encontrados em maior quantidade no óleo para todos os solventes empregados na sua extração foram o esteárico, elaídico, linoleico e palmítico, porém este último ausente na extração com éter de petróleo. Os ácidos graxos alfa-linoleico (ômega-3) e oleico (ômega 9) não foram identificados no óleo extraído das sementes de goiaba com os solventes utilizados. Conclui-se, portanto, que a extração de óleo a partir das sementes de goiaba é viável, podendo este produto ser uma nova fonte de óleo para consumo humano e matéria-prima para o setor farmacêutico e para a indústria de cosméticos.

\section{REFERÊNCIAS}

AQUiNO, A. C. M. S.; MÓES, R. S.; LEÃO.; FIGUEIREDO, A. V. D.; CASTRO, A. A. Avaliação físico-química e aceitação sensorial de biscoitos tipo cookies elaborados com farinha de resíduos de acerola. Rev. Inst. Adolfo Lutz, São Paulo, v.69, n.3, p. 379-86. 2010.

BRUM, A. A. S. Métodos de extração e qualidade da fração lipídica. 2004. 79 f. Dissertação (Mestrado em Ciência e Tecnologia de Alimentos) - Universidade de São Paulo, Piracicaba, 2004.

DAMIANI, C.; VILAS BOAS, E. V.; SOARES JUNIOR, M. S.; CALIARI, M.; PAULA, M. L.; PEREIRA, D. E. P.; SILVA, A. G. M. Análise física, sensorial e microbiológica de geléias de manga formuladas com diferentes níveis de cascas em substituição à polpa. Cienc Rural, Santa Maria, v.38, n.5, p.1418-142. 2008.

FONTANARI, G. G.; JACON, M. C.; PASTRE, I. A.; FERTONANI, F. L.; NEVES, V. A.; BATISTUTI, J. P. Isolado protéico de semente de goiaba (Psidium guajava): caracterização de propriedades funcionais. Cienc. Tecnol. Alimet., Campinas, v. 27, p. 73-79. 2007.

HARTMAN, L; LAGO, R.C.A. A rapid preparation of fatty methyl esters from lipids. Lab. Pract., London, v. 22, p. 475-477, 1973.

IAL. INSTITUTO ADOLFO LUTZ. Métodos físico-químicos para análise de alimentos. 1. ed. digital. São Paulo, 2008. 1020 p.

ISHIMOTO, F. Y.; HARADA, A. I.; BRANCO, I. G.; CONCEIÇÃO, W. A. S.; COUTINHO, M. R. Aproveitamento alternativo da casca do maracujá-amarelo (Passiflora edulis f. var. flavicarpa Deg.) para produção de biscoitos. RECEN, Guarapuava, v.9, n.2, p.179-292, jul.dez. 2007. 


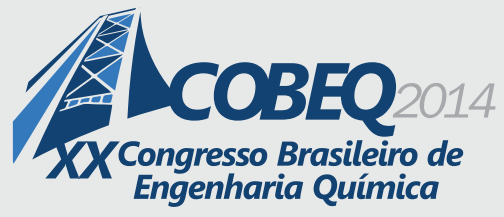

\section{9 a 22 de outubro de 2014 \\ Florianópolis/SC}

JARDINI, F. A.; MANCINI FILHO, J. Avaliação da atividade antioxidante em diferentes extratos da polpa e sementes da romã (Punica granatum, L.). Rev. Bras. Cienc. Farm., São Paulo, v. 43, n. 1, p. 137-147. 2007.

KOBORI, C. N.; JORGE, N. Caracterização dos óleos de algumas sementes de frutas como aproveitamento de resíduos industriais. Cienc. Agrotecnol, Lavras, v. 29, n. 5, p. 10081014. 2005.

LUZIA, D. M. M.; BERTANHA, B. J.; JORGE, N. Sementes de pitanga (Eugenia uniflora L.): potencial antioxidante e perfil de ácidos graxos. Rev. Inst. Adolfo Lutz, São Paulo, v. 69, n. 2, p.175-80. 2010.

LUZIA, D. M. M.; JORGE, N. Composição centesimal, potencial antioxidante e perfil dos ácidos graxos de sementes de jambolão (Syzygium cumini L.). Rev. Ciênc. Agron., Fortaleza, v.40, n.2, p.219-223. 2009.

MACEDO, B. A.; MAIA, G. A.; FIGUEIREDO, R. N.; ORIÁ, H. F.; GUEDES, Z. B. L. ARAÚJO FILHO, G. C. Propriedades físico-químicas e composição dos ácidos graxos da fração lipídica de sementes de quatro variedades de goiaba. B. CEPPA. Curitiba, v.12, n.1, p.55-64. 1994.

MALACRIDA, C. R.; ANGELO, P. M.; ANDREO, D.; JORGE, N. Composição química e potencial antioxidante de extratos de sementes de melão amarelo em óleo de soja. Rev. Ciênc. Agron., Fortaleza, v.38, n.4, p.372-376. 2007.

MELO, P. S.; BEGAMASHI, K. B.; TIVERON, A . P.; MASSAROLI, A. P.; OLDONI, T. L. C.; ZANUS, M. C.; PEREIRA, G. E.; ALENCAR, S. M. Composição fenólica e atividade antioxidante de resíduos agroindustriais. Cienc. Rural, Santa Maria, v.41, n.6, p.1088-1093. 2011.

NASCIMENTO, R. J.; ARAÚJO, C. R.; MELO, E. A. Atividade antioxidante de extratos de resíduo agroindustrial de goiaba (Psidium guajava L.). Alim. Nutr., Araraquara, v. 21, n. 2, p. 209-216. 2010.

PRASAD, N. B. L.; AZEEMODDIN, G. Characteristics and composition of guava (Psidium guajava L.) seed and oil. J. Amer. Oil Chem. Soc., Champaign, v. 71, n. 4. 1994.

ROCKENBACH, I. I.; RODRIGUES, E.; GONZAGA, L. V.; FETT, R. Composição de ácidos graxos de óleo de semente de uva (Vitis vinifera L. e Vitis labrusca L.). Braz. J. Food Technol, Campinas, III SSA, p. 23-26. 2010.

SANTOS, C. X. Caracterização físico-química e análise da composição química da semente de goiaba oriunda de resíduos agroindustriais. 2011. 61 f. Dissertação (Mestrado em Engenharia de Alimentos) - Universidade Estadual do Sudoeste da Bahia, Itapetinga, 2011.

TAKEMOTO, E.; OKADA, I. A.; GARBELOII, M. L.; TAVARES, M.; AUED-PIMENTEL, S. Composição química da semente e do óleo de baru (Dipteryx alata Vog.) nativo do Município de Pirenópolis, Estado de Goiás. Rev. Inst. Adolfo Lutz, São Paulo, v. 60, n. 2, p. 113-117. 2001.

UCHOA, A. M. A.; COSTA, J. M. C.; MAIA, G. A.; SIlVA, E. M. C.; CARVALHO, A. F. F. U.; MEIRA, T. R. Parâmetros físico-químicos, teor de fibra bruta e alimentar de pós alimentícios obtidos de resíduos de frutas tropicais. Segurança Alimentar e Nutricional, Campinas, v. 15, n. 2, p. 58-65. 2008. 